\title{
ESTUDO SOBRE A RELAÇ̃̃O ENTRE O NÍVEL DE ESTRESSE NO TRABALHO E O COMPROMETIMENTO COM A CARREIRA EM BANCÁRIOS DA BAHIA
}

\author{
Bianca Saionara Lima Pessôa ${ }^{1}$; Paulo Wenderson Teixeira Moraes ${ }^{2}$ \\ 1. Bolsista PIBIC/FAPESB, Graduanda em Psicologia, Universidade Estadual de Feira de Santana, e-mail: \\ biaslp@homail.com \\ 2. Orientador, Departamento de Ciências Humanas e Filosofia, Universidade Estadual de Feira de Santana, e-mail: \\ pwmoraes@yahoo.com
}

PALAVRAS-CHAVE: Estresse; Comprometimento com a carreira; fatores psicossociais.

\section{INTRODUÇÃO}

O trabalho constitui-se como um fator importante na formação das sociedades, pois através dele o homem constrói o seu ambiente e a si mesmo (Oliveira, Santos e Cruz, 2007). Apesar dos aspectos positivos relacionados às atividades laborais, o excesso de estresse é um dos fenômenos que vem sendo frequentemente relacionado ao fator trabalho. Cada um, entretanto, pode reagir de forma singular ao estresse. Estudiosos das estratégias de enfrentamento (coping) sustentam que a resposta a um mesmo evento estressor pode variar de pessoa para pessoa (Regehr, Hemsworth \& Hill, 2001 apud Servino, Rabelo e Campos, 2013). Dentre esses recursos, há o comprometimento com a carreira que está relacionado com a motivação e a produtividade do trabalhador (Blau, 1989, 2001apud Lee, Carswell, \& Allen, 2000). O compromisso adequado surge num contexto de reciprocidade e difere do contexto no qual o comprometimento excessivo com o trabalho aumenta o estresse e pode impactar agravando muitos sintomas, como por exemplo, os sintomas de LER/DORT (Siegrist, 2001).

Todavia, de acordo com Moraes (2014), ainda é pouco explorada a relação entre comprometimento com a carreira e a saúde do trabalhador. Possivelmente existe uma relação de mão dupla, onde tanto um trabalhador comprometido com sua carreira desenvolve uma capacidade maior de lidar com o estresse e manter-se saudável, como o caminho inverso. Para o autor, existe uma relação entre o comprometimento com a carreira e o estresse. Visando investigar, através dos instrumentos de pesquisa disponíveis pela tese de doutorado de Moraes (2014), procurei por meio deste plano de trabalho, estudar a relação entre o nível de estresse no trabalho e o comprometimento com a carreira em bancários do Estado da Bahia e analisar os diferentes modelos de estresse no trabalho e a relação com o compromisso na carreira, de forma a possibilitar uma nova forma de abordagem dos problemas relacionados ao estresse no trabalho, fundamentando e legitimando a necessidade de acompanhamento e planejamento da carreira dos trabalhadores, constituindo mais uma dimensão de cuidado ao trabalhador.

\section{MATERIAL E MÉTODOS}

Houve análise da coleta de dados já existentes, por meio da tese de Doutorado do Dr. Paulo Moraes. Os dados de estresse e comprometimento com a carreira foram analisados por meio do programa estatístico (SPSS- Statistical Packcage for Social Science, versão 17.0). Em seguida, as informações foram sistematizadas em tabelas e gráficos com auxílio do Programa Excel da Microsoft Corporation. Foram utilizadas também as escalas do modelo DER (Desequilíbrio-Esforço-Recompensa) (Siegrist, 2001) e as escalas do modelo Demanda 
Controle (Karasek, 1998) para investigar, através da correlação, os fatores psicossociais associados ao estresse. Para analisar o estresse psíquico, foram utilizados 16 itens da escala do Questionário de Saúde Geral (QSG) (Pasquali et AL, 1998). Para mensurar o comprometimento com a carreira foi utilizada a versão traduzida e aplicada no contexto brasileiro por Magalhães (2005) do instrumento elaborado por Carson e Bedeian (1994), que utiliza uma escala de 1 a 5 com os fatores: identidade, planejamento e resiliência.

\section{ANÁLISE E DISCUSSÃO DOS RESULTADOS}

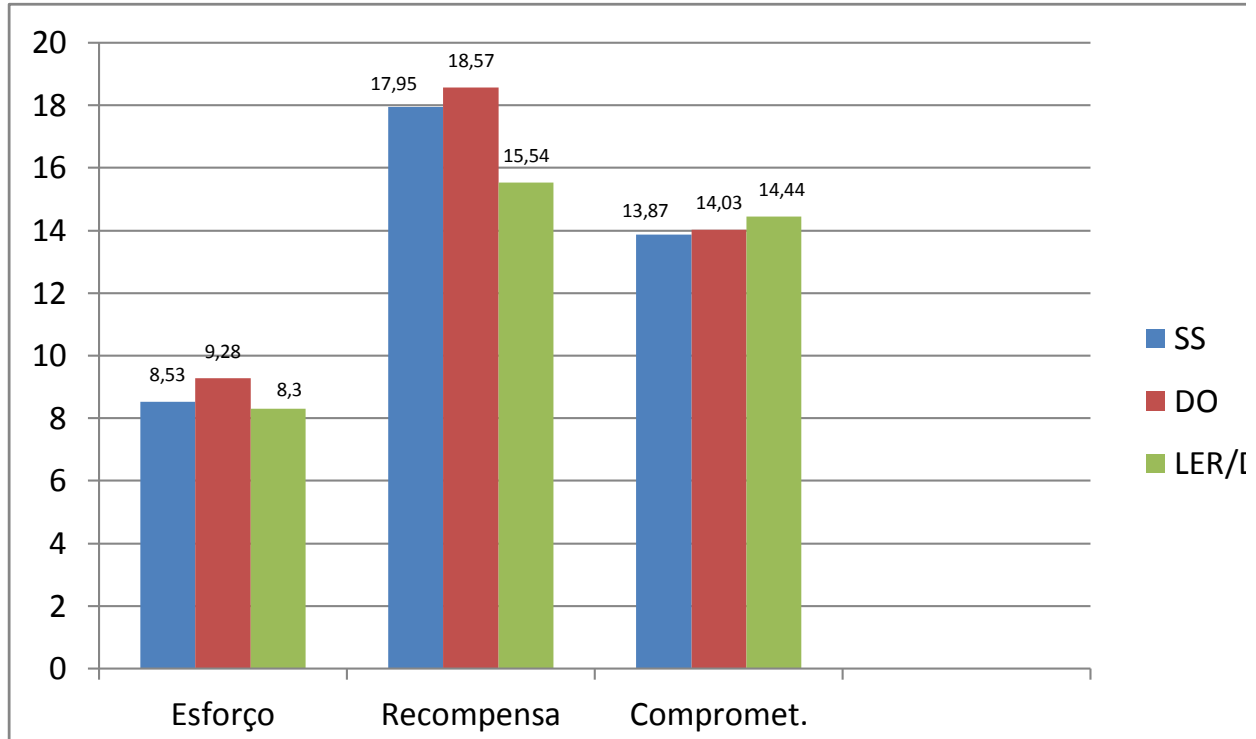

Gráfico 01: Médias de Esforço, Recompensa e Comprometimento Excessivo em Bancários da Bahia da amostra de $2013(n=220)$

Legenda:

SS: Sem Sintomas

DO: Dores Osteomusculares

LER/DORT; Lesão por Esforço Repetitivo/ Doenças Osteomusculares Relacionadas ao Trabalho

Diferença entre médias estatisticamente significativa, $\mathrm{p}<0,05^{* *}$

Diferença entre médias estatisticamente significativa, $\mathrm{p}<0,01$

*** Diferença entre médias estatisticamente significativa, $\mathrm{p}<0,001$

No gráfico 01, o qual apresenta as médias de esforço, recompensa e comprometimento excessivo, em uma amostra de bancários da Bahia (2013), há um dado interessante, onde as pessoas que relataram apenas dores osteomusculares apresentam média maior $(9,28)$ de relato de esforço do que as pessoas que relataram diagnóstico de LER/DORT $(8,30)$, sendo que as pessoas que não relataram nenhum sintoma também apresentam média de relato de esforço maior $(8,53)$ do que as pessoas que relataram diagnóstico de LER/DORT(p<0,001).

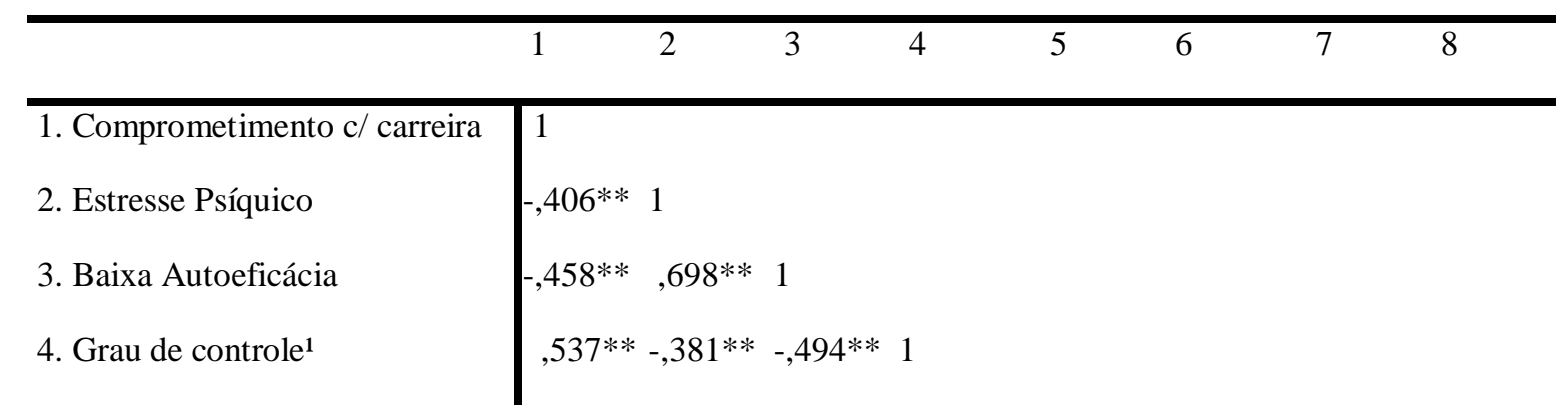




\begin{tabular}{|c|c|c|c|c|c|c|c|c|}
\hline 5. Demanda Psicológica ${ }^{1}$ &,- 081 &, $247 * *$ &, 051 &,- 001 & 1 & & & \\
\hline 6. Esforço ${ }^{2}$ &,- 129 &, $212 *$ & ,057 & ,111 &, $610^{* *}$ & & & \\
\hline 7. Recompensa ${ }^{2}$ &, $596 * *$ &,$- 434 * *$ &,$- 507 * *$ &, $522 * *$ &,$- 138 * *$ &,$- 136^{*}$ & 1 & \\
\hline 8. Comprometimento Excessivo² &,$- 182 * *$ &, $491 * *$ &, $368 * *$ & -071 &, $399 * *$ &, $454 * *$ &,$- 310^{* *}$ & 1 \\
\hline 9. $\mathrm{DER}^{2}$ &,$- 477 * *$ &, $419 * *$ &, $365 * *$ &,$- 293^{* *}$ &, $448 * *$ &, $642^{* *}$ &,$- 775^{* *}$ &, $455^{* *}$ \\
\hline
\end{tabular}

Tabelo 01 - Correlações entre Comprometimento com a Carreira, modelo Demanda-Controle e modelo DER, numa amostra de bancários, Bahia, $2013(\mathrm{n}=\mathbf{2 2 0})$

Legenda:

DER: Desequilíbrio Esforço- Recompensa

* $\mathrm{p}<0,01$

$* * \mathrm{p}<0,001$

${ }^{1}$ Modelo Demanda-Controle-Suporte Social de Karasek (1998)

${ }^{2}$ Modelo Desequilíbrio Esforço-Recompensa de Siegrist (2009)

A subescala de grau de controle e a de recompensa apresentaram uma correlação de 0,522 ( $\mathrm{p}<0,001$ ). Já a subescala de demanda psicológica apresentou uma forte correlação com esforço de $0,610(\mathrm{p}<0,001)$. A subescala de esforço apresentou uma forte correlação de 0,642 ( $\mathrm{p}<0,001)$ com o modelo DER (Desequilíbrio Esforço- Recompensa) e a subescala de recompensa apresentou também uma forte correlação negativa com o modelo DER de $-0,775$ ( $\mathrm{p}<0,001)$, essas correlações são esperadas, pois o esforço faz parte do cálculo do modelo DER. Comprometimento com a carreira e comprometimento excessivo apresentaram uma forte correlação negativa de $-0,182(\mathrm{p}<0,001)$.

\section{CONSIDERAÇÕES FINAIS}

O presente estudo mostrou que, em 2013, os bancários que participaram da pesquisa apresentaram um grau de estresse significativo. Os bancários que apresentaram a maior média de relato de estresse, também apresentaram as maiores médias de relato de percepção de baixa eficácia no trabalho.

Nos resultados do gráfico 01, pode-se notar que, os bancários que tinham o diagnóstico de Ler/Dort apresentaram relato de percepção de menor esforço, pode-se inferir que, dada a situação do diagnóstico e a redistribuição de cargos devido a este fator, o bancário que é diagnosticado com alguma lesão, muitas vezes, é remanejado de cargo e ele tem uma percepção de menor esforço no trabalho comparado aos bancários que não apresentaram sintomas e aos bancários que apresentaram apenas dores osteomusculares. Nota-se também na tabela 01 que, existe uma correlação negativa entre estresse e comprometimento com a carreira e a forte correlação positiva entre estresse e comprometimento excessivo e isso, evidencia mais uma vez como estar comprometido com a carreira é algo saudável e estar comprometido excessivamente com a carreira não é saudável para o trabalhador.

Quando o indivíduo começa a comprometer-se de forma excessiva com a empresa, por conta de vários fatores, como uma postura defensiva por insegurança no trabalho, por exemplo, por consequência ele tende a ficar mais estressado e vice- versa. Portanto, é necessário investir na saúde do trabalhador e a atenção integral à saúde dos trabalhadores abrange as ações de promoção e proteção da saúde, de vigilância e de assistência incluindo a 
reabilitação (DSAST, 2010). A procura por esta qualidade, não pode ser considerada apenas como um custo para as empresas, uma vez que os custos com afastamentos e ações trabalhistas são maiores do que uma medida preventiva. Cada empresa deve começar a fazer a sua parte para a mudança cultural das práticas de saúde e de minimização de riscos no ambiente de trabalho, pois é através das práticas de prevenção de riscos ocupacionais, que os ganhos secundários aparecerão. Portanto, humanizar o ambiente de trabalho e acompanhar a carreira do trabalhador, favorecerá um clima mais saudável no mesmo, diminuindo os fatores de risco associados ao ambiente laboral.

\section{REFERÊNCIAS}

OLIVEIRA, Hilderline Câmara de. , SANTOS, Joseneide Sousa Pessoa dos. , CRUZ, Eduardo Franco Correia. O Mundo do Trabalho: Concepções e Historicidade. Universidade Federal Do Maranhão, Programa De Pós-graduação Em Políticas Públicas. III Jornada Internacional De Políticas Públicas. Questão social e desenvolvimento no século XXI, São Luís, Maranhão, 2007.

SIEGRIST, J. (2001). A Theory of Occupational Stress. In J. Dunham (Ed.), Stress in the Workplace: Past, Present and Future (pp. 52-66). London: Whurr Publishers.

MORAES, P. W. T. O efeito dos fatores psicossociais e dos vínculos com a carreira nos sintomas de LER/DORT entre bancários da Bahia. 2014. 209 (Doutorado). Instituto de Psicologia, Universidade Federal da Bahia, Salvador.

SERVINO, Sandro, RABELO, Elaine, CAMPOS, Neiva e Rodrigo Pires De., Estresse Ocupacional e Estratégias de Enfrentamento entre profissionais de tecnologia da informação. Universidade Católica de Brasília e Universidade de Brasília, Brasília, Brasil, Revista Interinstitucional de Psicologia, 2013.

LEE, G. K.; CARSWELL, J. J.; ALLEN, N. J. A meta-analytic review of occupational commitment: relations with person- and work-related variables. J Appl Psychol, v. 85, n. 5, p. 799-811, Oct., 2000. PASQUALI, L., GOUVEIA, V. V., ANDRIOLA, W. B., MIRANDa, F. J., \& RAMOS, A. L. M. (1996). Questionário de saúde geral de Goldberg: Manual técnico QSG (adaptação brasileira). São Paulo: Casa do Psicólogo. São Paulo: Casa do Psicólogo.

CARSON, K. D., \& BEDEIAN, A. G. (1994). Career Commitment: Construction of a Measure and Examination of Its Psychometric Properties. Journal of Vocational Behavior, 44(3), 237-262.

KARASEK, R. A., BRISSON, C., KAWAKAMI, N., HOUTMAN, I., BONGERS, P., \& AMICK, B. (1998) The Job Content Questionnaire (JCQ): an instrument for internationally comparative assessments of psychosocial job characteristics. Journal of Occupational Health Psychology, 3(4), 322-355.

MAGALHAES, M. d. O. (2005). Personalidades vocacionais e desenvolvimento na vida adulta: generatividade e carreira profissional. (Tese), Universidade Federal do Rio Grande do Sul, Porto Alegre. 